\title{
Simulation Based Teaching Of Power Electronics
}

\author{
Rama Rao P.V.V., G. Durga Prasad ${ }^{2}$, Jagateswar Patra ${ }^{3}$ \\ ${ }^{1}$ Member-IEEE, Professor \& Head, EEE, ${ }^{2}$ Assistant Professor of EEE, ${ }^{3}$ Professor in EEE \\ ${ }^{1.2,3}$ Shri Vishnu Engineering College for Women, Bhimavaram, Andhra Pradesh \\ 1'pvvmadhuram@gmail.com,durgaprasad,2.garapati@svecw.edu.in,jagateswar26@svecw.edu.in
}

\begin{abstract}
Simulation based approach to teach the Power Electronic course is proposed in this paper. The simulation tool is oriented towards Electrical and Electronics Engineering (EEE) students at the undergraduate level, enrolled in courses such as Power Electronics, Power Semiconductor drives or the like. The proposed teaching methodology is demonstrated by simulation example of a realistic converter system. The paper discusses the MATLAB/ SIMULINK tool and the implementation of simulation for enhancing student learning ability of complex power electronic systems.
\end{abstract}

Keywords-Teaching Methodology, Power Electronics, Simulation Tools, Course Evaluation

\author{
Rama Rao P.V.V. \\ Member-IEEE \\ Professor \& Head, EEE \\ Shri Vishnu Engineering College for Women, \\ Bhimavaram, Andhra Pradesh \\ pvvmadhuram@gmail.com
}

\section{Introduction}

Simulation software is based on the process of modeling a real phenomenon with a set of mathematical formulas. It is, essentially, a program that allows the user to observe an operation through simulation without actually performing that operation. Simulation software is developed to model and design equipment so that the final product will be as close to design as possible with no expense in process modification. Simulation tool with real-time response is often used in designing, which has gained researchers interest to develop industry specific application equipment. Simulation Tools are also getting recommended to learn many engineering courses for the students to better understanding of the content. The computer simulation has become a great teaching aid or instructional tool for an introductorylevel power electronics course has increased students' abilities to comprehend the behavior of several power electronics circuits, giving valuable training experience to achieve the learning outcome [1].

Many simulation software packages provide a user-friendly environment that allows the undergraduate students in electrical engineering to simulate the power system behavior, power electronics and drives applications, electronic circuits, feedback control systems etc. In theory, any phenomena that can be reduced to mathematical data and equations can be simulated on a computer. Simulation can be difficult because most natural phenomena are subject to an almost infinite number of 
influences [2]. A PC-based computer program, which runs under the Windows environment, has been developed at Purdue University Calumet [3]. A blockoriented digital simulation package is proposed to aid instruction and research in control of electric drives, power systems, and power electronic circuits. The software tool consists of several pre-defined blocks stored in a library; these blocks can be called from the library and interconnected as required, based on the mathematical model of the system to be simulated [4].

Complex circuit dynamics and typical concepts are involved in Electrical Engineering subjects. Hence it is difficult to teach the course and making the under graduate students to understand in the class room itself. A new software tool for learning the dynamic behavior of power electronics circuits is developed for undergraduate students. This tool incorporates the merits of two well-known software packages, namely, the realistic time-domain simulation of PSpice and the parametric identification process of MATLAB [5]. Power Electronics is a professional course with a strong theoretical and practical base. The objectives of this course are: grasping the topology of a variety of power electronic circuits; the operating principles; control methods; design calculations and practical skills; and to be familiar with the scope of applications for the various power electronic devices, and other technical and economic matters. Presented an overview of the development of e-learning materials in allied field of power electronics and shown some hints to optimized design from view of purpose of its utilization [6].

In order to unify the power electronic circuit analysis a building block is identified in commonly used power converter topologies in the first course in power electronics. The use of space vectors is introduced on a physical basis to describe operation of ac machines in steady state in the first course of electric drives, thereby teaching students what they need to learn, making these courses appealing, and providing a seamless continuity to advanced courses [7]. E-learning platform possesses the advantages of hardware flexibility, friendly user interface, provision for distance waveform measurements, and removal of laboratory time and space constraints [8].

This paper proposes the simulink environment to learn the Power Electronics course more easily. The teacher can demonstrate visually the dynamic system behavior by changing the input parameters. This improves the quality of teaching by making the abstract concrete, the boring interesting and stimulates students' interest.

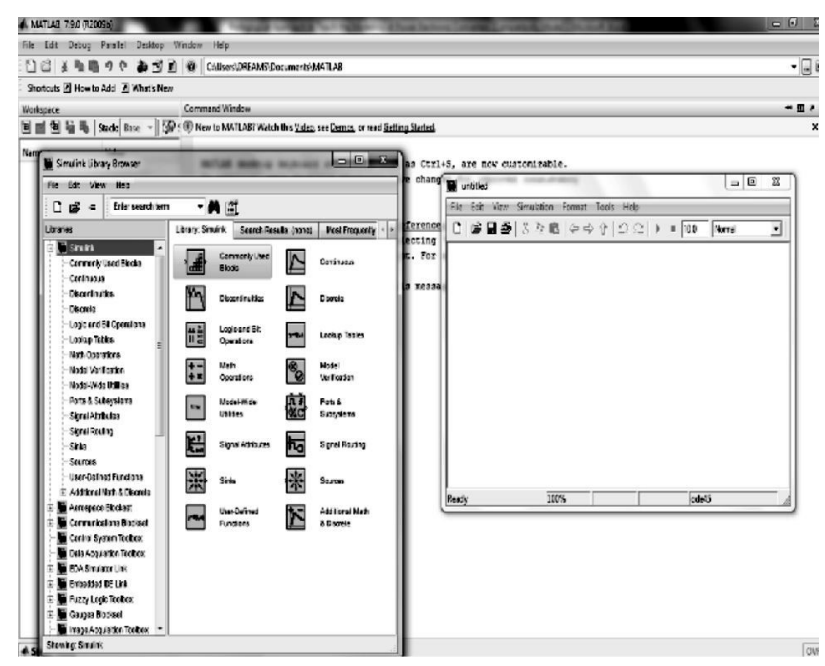

Fig. 1. MATLAB/ SIMULINK Window

\section{Model Based Learning}

Model-Based Design is a process that enables faster, more cost-effective development of dynamic systems, including control systems, signal processing, and communications systems. In Model-Based Design, a system model is at the center of the development process, from requirements development, through design, implementation, and testing. The model is an executable specification that you continually refine throughout the development process. The fig. 1 shows the window of the MATLAB/SIMULINK.

After model development, simulation shows whether the model works correctly. When software and hardware implementation requirements are included, such as fixed-point and timing behavior, you can automatically generate code for embedded deployment and create test benches for system verification, saving time and avoiding the introduction of manually coded errors.

Model-Based Design improves efficiency by:

( Using a common design environment across project teams

口 Linking designs directly to requirements

u Integrating testing with design to continuously identify and correct errors 
" Refining algorithms through multi-domain simulation

" Automatically generating embedded software code

૫ Developing and reusing test suites

( Automatically generating documentation

口 Reusing designs to deploy systems across multiple processors and hardware targets.

There are six steps in modeling any system:

1. Defining the System

2. Identifying System Components

3. Modeling the System with Equations

4. Building the Simulink Block Diagram

5. Running the Simulation

6. Validating the Simulation Results

\section{Simulation Examples}

\section{A. Open the Simulink Library Browser}

Run MATLAB before opening the Simulink Library Browser. Then open the Simulink Library Browser from the MATLAB Tool strip by clicking the Simulink Library button (). If not already loaded Simulink, a short delay occurs while it loads. The Library Browser opens. To keep the Library Browser above all other windows on desktop, in the Library Browser, select View $>$ Stay on Top.

B. Create a new Simulink model from Simulink Library

From the Simulink Library Browser menu, select File $>$ New $>$ Model. An empty model opens in the Simulink Editor. In the Simulink Editor, select File > Save. In the Save As dialog box, enter a name for your model, and then click Save. Simulink saves your model.

\section{Single-phase dual converter}

The single phase full converters with inductive loads allow only a two quadrant operation. If two of these full converters are connected back to back, both the output voltage and the load current flow can be reversed. The system provides a four - quadrant operation and is called a dual converter. Dual converters are normally used in high power variable speed drives. Because the instantaneous output voltages of the two converters are out of phase, there can be an instantaneous voltage difference and this can result in circulating current between the two converters.

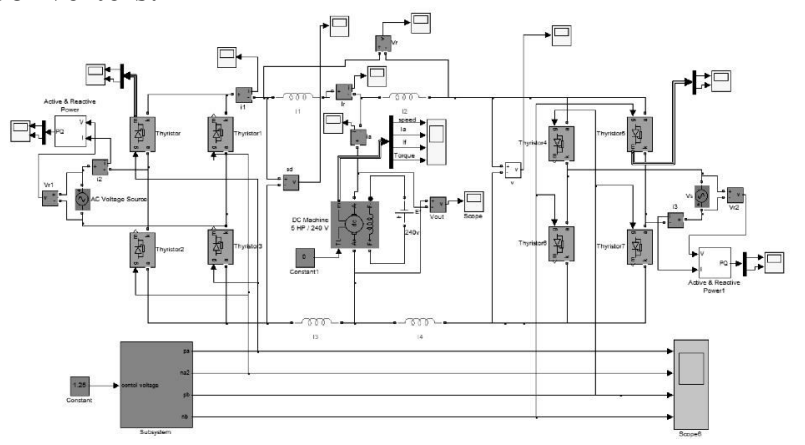

Fig. 2. Simulink diagram of dual converter fed DC motor drive

The fig.2 shows the Simulink diagram of dual converter fed DC motor drive. The results of dual converter fed dc motor drive; output voltage is shown in fig.3, Speed-torque characteristics in fig. 4 .

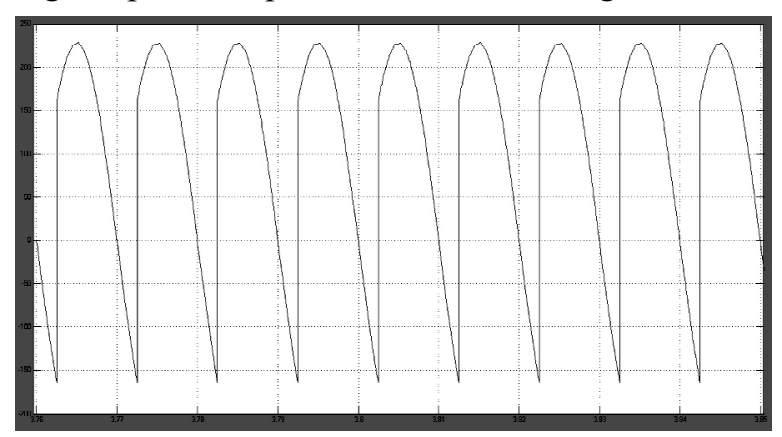

Fig. 3. Output voltage across Rectifier

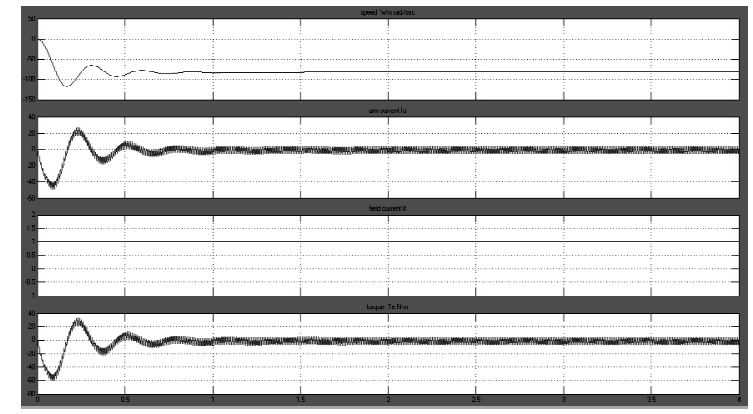

Fig. 4. Simulation results of speed, armature current, field current \& torque 


\section{Results And Discussion}

The table II gives course end survey for the PE. This survey is done in order to perform a qualitative evaluation of the delivery methodology adopted to make the students comfortable, consisting of nine questions which try to elicit their anonymous opinions on the effectiveness of its various features, on a fivepoint scale ranging from 1 (No Comment) to 5 (Excellent). According to the results, the proposed platform has good rating compared to the previous teaching methodology in power electronics and power semiconductor drives course in Shri Vishnu Engineering College for Women (SVECW). By using the ST based learning the student results has improved. Students can also develop the programming skills by generating the switching pulses for power semiconductor devices using M-File instead of using pulse generator directly; this helps the students to get the placement in software companies as well. One of the primary advantages of ST is that they are able to provide students with practical feedback when designing real world systems. This allows the students to determine the correctness and efficiency of a design before the system is actually constructed. Consequently, the user may explore the merits of alternative designs without actually physically building the systems. By investigating the effects of specific design decisions during the design phase rather than the construction phase, the overall cost of building the system diminishes significantly. Another benefit of ST is that they permit students to study a problem at several different levels of abstraction. By approaching a system at a higher level of abstraction, the student is better able to understand the behaviors and interactions of all the high level components within the system and is therefore better equipped to counteract the complexity of the overall system. This complexity may simply overwhelm the student if the problem had been approached from a lower level. As the student better understands the operation of the higher level components through the use of the simulator, the lower level components may then be designed and subsequently simulated for verification and performance evaluation as the students are using the simulation tools and learning the subjects they can have the meaningful understanding of the concepts and they can understand the system behavior. Based on the above discussion, we in SVECW adopted the Simulation based learning and we achieved a good result. The evaluation of software tool used for PE is shown in figure 7.According to the results, the proposed platform has good rating compared to the previous teaching method as shown in fig.5.

Table 1. Questionnaire for evaluation of the simulation based learning

\begin{tabular}{|c|c|c|c|c|c|c|}
\hline $\begin{array}{l}\text { S. } \\
\text { NO. }\end{array}$ & QUESTIONAIRE & $\begin{array}{l}\mathbf{E} \\
5\end{array}$ & $\begin{array}{l}G \\
4\end{array}$ & $\begin{array}{l}\mathbf{A} \\
3\end{array}$ & $\begin{array}{l}\mathbf{P} \\
2\end{array}$ & $\begin{array}{c}\mathrm{NC} \\
1 \\
\end{array}$ \\
\hline 1 & $\begin{array}{l}\text { Has the course achieved its } \\
\text { Course objectives? }\end{array}$ & $\square$ & $\square$ & $\square$ & $\square$ & $\square$ \\
\hline 2 & $\begin{array}{l}\text { Whether the faculty has } \\
\text { helped in acquiring the course } \\
\text { objectives? }\end{array}$ & $\square$ & $\square$ & $\square$ & $\square$ & $\square$ \\
\hline 3 & $\begin{array}{l}\text { Whether the faculty has given } \\
\text { real time application of the } \\
\text { subject? }\end{array}$ & $\square$ & $\square$ & $\square$ & $\square$ & $\square$ \\
\hline 4 & $\begin{array}{l}\text { Can you design simple power } \\
\text { electronic converter circuits } \\
\text { using simulation tool? }\end{array}$ & $\square$ & $\square$ & $\square$ & $\square$ & $\square$ \\
\hline 5 & $\begin{array}{l}\text { Can you study the } \\
\text { characteristics of a Power } \\
\text { Semiconductor Device using } \\
\text { simulation Tool? }\end{array}$ & $\square$ & $\square$ & $\square$ & $\square$ & $\square$ \\
\hline 6 & $\begin{array}{l}\text { Are you able to design } \\
\text { various inverter circuits? }\end{array}$ & $\square$ & $\square$ & $\square$ & $\square$ & $\square$ \\
\hline 7 & $\begin{array}{l}\text { Have you gained knowledge } \\
\text { about PWM technique? }\end{array}$ & $\square$ & $\square$ & $\square$ & $\square$ & $\square$ \\
\hline 8 & $\begin{array}{l}\text { Are you satisfied with the } \\
\text { course outcomes met through } \\
\text { this subject? }\end{array}$ & & YES & & $\square \mathrm{NO}$ & \\
\hline 9 & $\begin{array}{l}\text { If your answer is No, please } \\
\text { indicate your preferences: } \\
\text { More inputs, additional } \\
\text { contents, real life examples }\end{array}$ & & $\square \mathrm{YE}$ & & $\square \mathrm{N}$ & \\
\hline
\end{tabular}

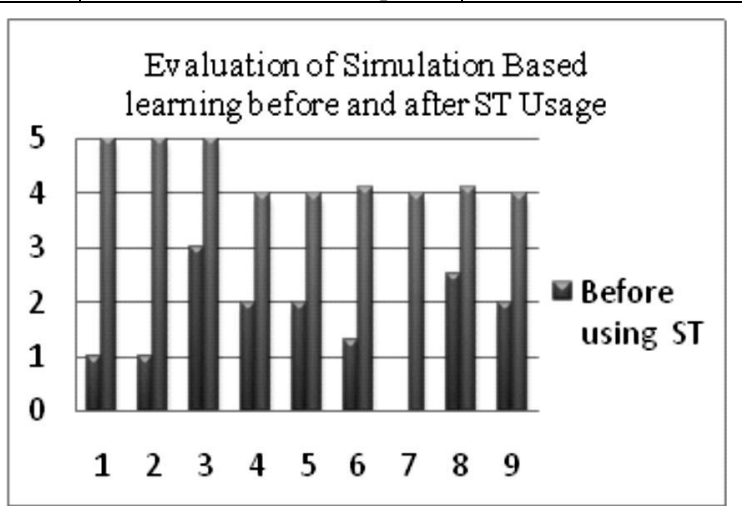

Fig. 5. Evaluation of Simulation Based Learning before and after usage of simulation Tools 


\section{Conclusion}

In this paper the effectiveness of teaching by using MATLAB/ Simulink simulation software tool is explained by modeling and simulating the Dual Converter Fed Four Quadrant DC Motor Drive as an example in teaching one of the power electronic converter circuits. By introducing simulation tools based learning in the classroom environment the students can gain more practical knowledge and no real hardware environment and resources are required. This makes the students to feel that they are working in real time environment and this methodology will increase the confident level of the student in that course. Survey results also show the enhanced student interest in learning the concepts using simulation software rather than chalk and board methodology.

\section{References}

[1]D. W. Hart, "Circuit simulation as an aid in teaching the principles of power electronics," IEEE Transactions on Education, Vol. 36, No. 1, pp. 10-16, Feb. 1993.

[2] Simulation definition [on line]. [cit. 2010-05-10]. http://www.webopedia.com/TERM/S/simulation. html.

[3] Ahmed A. and Bee J.M., "Computer simulation of electric power system", Proceedings of Frontiers in Education Conference, pp. 2c6.5 - 2c6.8 vol.1, 1-4 Nov. 1995.
[4] Buchner P. and Nehiri M.H., "A block-oriented PC-based simulation tool for teaching and research in electric drives and power systems" IEEE Transactions on Power Systems, Vol. 6, No. 3, pp. 1299-1304, Aug. 1991.

[5] G. G. Karady and G. T. Heydt, "Increasing student interest and comprehension in power engineering at the graduate and undergraduate levels," IEEE Trans. Power Syst., vol. 15, no. 1, pp. 16-21, Feb. 2000.

[6] V. Fed'ak and P. Bauer, "E-learning in education of electrical drives and power electronics: Opportunities and challenges," in International Conference on Electrical Drives and Power Electronics, Dubrovnik, CROATIA, September 2005.

[7] N. Mohan, W. P. Robbins, P. Imbertson, T. M. Undeland, R. C. Panaitescu, A. K. Jain, P. Jose, and T. Begalke, "Restructuring of first courses in power electronics and electric drives that integrates digital control," IEEE Transactions on Power Electronics, Vol. 18, No. 1, pp. 429-437, Jan. 2003.

[8]S.-C. Wang and Y.-H. Liu, "Softwarereconfigurable e-learning platform for power electronics courses," IEEE Transactions on Industrial Electronics, Vol. 55, No. 6, pp. 24162424, June 2008. 